\title{
Green synthesis of gold nanoparticles using
} Euphrasia officinalis leaf extract to inhibit lipopolysaccharide-induced inflammation through NF- $\kappa B$ and JAK/STAT pathways in RAW 264.7 macrophages

This article was published in the following Dove Medical Press journal: International Journal of Nanomedicine

\author{
Ying Liu' \\ Senghyun Kim² \\ Yeon Ju Kim ${ }^{1,2}$ \\ Haribalan Perumalsamy ${ }^{2}$ \\ Seungah Lee ${ }^{3}$ \\ Eunson $\mathrm{Hwang}^{4}$ \\ Tae-Hoo $\mathrm{Yi}^{1,2}$ \\ 'Graduate School of Biotechnology, \\ College of Life Sciences, Kyung Hee \\ University, Yongin-si, Gyeonggi-do, \\ Republic of Korea; ${ }^{2}$ Department of \\ Oriental Medicinal Biotechnology, \\ College of Life Sciences, Kyung Hee \\ University, 1732, Deogyeong-daero, \\ Giheung-gu, Yongin-si, Gyeonggi-do \\ 17104, Republic of Korea; \\ ${ }^{3}$ Department of Applied Chemistry \\ and Institute of Natural Sciences, \\ College of Applied Science, Kyung \\ Hee University, Yongin-si, Republic of \\ Korea; ${ }^{4}$ Snow White Factory Co., Ltd., \\ Gangnamgu, Seoul, Republic of Korea
}

Correspondence: Yeon Ju Kim;

Tae-Hoo Yi

College of Life Sciences, Kyung Hee

University, I732, Deogyeong-daero,

Giheung-gu, Yongin-si, Gyeonggi-do

17104, Republic of Korea

Tel +8 23। 20। 2645

Fax +8 23I 2048116

Email yeonjukim@khu.ac.kr;

drhoo@khu.ac.kr
Background: Gold nanoparticles (AuNPs) have potential applications in the treatment and diagnosis process, which are attributed to their biocompatibility and high efficiency of drug delivery. In the current study, we utilized an extract of Euphrasia officinalis, a traditional folk medicine, to synthesize gold nanoparticles (EO-AuNPs), and investigated their anti-inflammatory effects on lipopolysaccharide (LPS)-stimulated RAW 264.7 macrophages.

Materials and methods: The AuNPs were synthesized from an ethanol extract of $E$. officinalis leaves and characterized using several analytical techniques. Anti-inflammatory activities of EO-AuNPs were detected by a model of LPS-induced upregulation of inflammatory mediators and cytokines including nitric oxide (NO), inducible nitric oxide synthase (iNOS), tumor necrosis factor- $\alpha$ (TNF- $\alpha$ ), IL-1 $\beta$, and IL-6 in RAW 264.7 cells. The activation of nuclear factor (NF)- $\kappa \mathrm{B}$ and Janus kinase/signal transducer and activators of transcription (JAK/STAT) signaling pathways was investigated by Western blot.

Results: The results confirmed the successful synthesis of AuNPs by E. officinalis. Transmission electron microscopy images showed obvious uptake of EO-AuNPs and internalization into intracellular membrane-bound compartments, resembling endosomes and lysosomes by RAW 264.7 cells. Cell viability assays showed that EO-AuNPs exhibited little cytotoxicity in RAW 264.7 cells at $100 \mu \mathrm{g} / \mathrm{mL}$ concentration after 24 hours. EO-AuNPs significantly suppressed the LPS-induced release of NO, TNF- $\alpha$, IL-1 $\beta$, and IL- 6 as well as the expression of the iNOS gene and protein in RAW 264.7 cells. Further experiments demonstrated that pretreatment with EO-AuNPs significantly reduced the phosphorylation and degradation of inhibitor kappa B-alpha and inhibited the nuclear translocation of NF- $\kappa$ B p65. In addition, EO-AuNPs suppressed LPS-stimulated inflammation by blocking the activation of JAK/STAT pathway.

Conclusion: The synthesized EO-AuNPs showed anti-inflammatory activity in LPS-induced RAW 264.7 cells, suggesting they may be potential candidates for treating inflammatorymediated diseases.

Keywords: gold nanoparticles, Euphrasia officinalis, lipopolysaccharide, LPS, inflammatory, NF- $\kappa$ B, JAK/STAT

\section{Introduction}

Inflammation is an immune system's defensive response to harmful stimuli, such as pathogens, damaged cells, toxic compounds, or irradiation, which acts by removing 
injurious stimuli and initiating the healing process. Prolonged and severe inflammatory responses may give rise to many progressive diseases, including cancer, cardiovascular disease, diabetes, and autoimmune conditions. ${ }^{1}$ As part of the innate immune system, macrophages are commonly applied to investigate immunoregulatory and anti-inflammatory agents. Lipopolysaccharide (LPS), the major component of the outer cell membrane of Gram-negative bacteria, can activate macrophages and produce large amounts of proinflammatory mediators and cytokines, including nitric oxide (NO), tumor necrosis factor (TNF)- $\alpha$, IL-1 $\beta$, and IL-6. ${ }^{1} \mathrm{NO}$ is an unorthodox messenger molecule, which can be generated by inducible nitric oxide synthase (iNOS) in LPS-stimulated macrophages. ${ }^{2}$ LPS is also recognized by the immune system as a marker for the detection of bacterial pathogen invasion that is responsible for the development of inflammatory response and, in extreme cases, endotoxic shock. Studies show that regulation of the production of these mediators and cytokines can effectively control inflammation. ${ }^{3}$ Antiinflammatory drugs reduce pain, decrease fever, prevent blood clots, and, in higher doses, decrease inflammation. Side effects depend on the specific drug, but largely include an increased risk of gastrointestinal ulcers and bleeds, heart attack, and kidney disease. ${ }^{4}$ We need to apply natural antiinflammatory factors within medication therapy to achieve an increased pharmacological response and the lowest degree of unwanted side effects. Therefore, medicinal plants and their secondary metabolites are progressively being used in the treatment of diseases as complementary medicines. ${ }^{5}$

LPS works as a pathogen-associated molecular pattern and binds to the Toll-like receptor 4 (TLR4) of host cells. ${ }^{6}$ Activated TLR4 recruits downstream factors and initiates intracellular signaling cascades. Nuclear factor kappa B $(\mathrm{NF}-\kappa \mathrm{B})$ is a redox-sensitive transcription factor that is responsible for the expression of pro-inflammatory genes. ${ }^{7}$ $\mathrm{NF}-\kappa \mathrm{B}$ is sequestered by inhibitor kappa B-alpha $(\mathrm{I} \kappa \mathrm{B} \alpha)$ within the cytoplasm of unstimulated cells. LPS activates the inhibitor kappa B kinase complex, resulting in the ubiquitination and subsequent degradation of $\mathrm{I} \kappa \mathrm{B} \alpha$, allowing $\mathrm{NF}-\kappa \mathrm{B}$ to translocate to the nucleus and induce the expression of target genes. ${ }^{8}$ The Janus kinase/signal transducer and activators of transcription (JAK/STAT) pathway is also critical for mediating inflammatory responses. With the binding of LPS to their receptors, the receptor-associated tyrosine kinase family of JAKs becomes activated, which consequently leads to the phosphorylation of STAT1. In turn, STAT1 translocates into the nucleus, where it acts as a transcription factor, inducing iNOS expression and enhancing NO production. ${ }^{9}$
Due to their ease of synthesis, functionalization, and biocompatibility, nanoparticles (NPs) have been widely applied in nanomedicine and biomedical applications, such as drug delivery, cancer treatment, virus detection, antiinflammatory activity, and immunosuppressive effects; they have also been used actively in the identification of chemical and biological agents. ${ }^{10-12}$ Recently, much attention has been paid to exploring protein or peptide-mediated biomimetic NPs because of the advantages of high bioactivity efficacy, enhanced biocompatibility, and less side effects on health tissues. ${ }^{13-15}$ Although nanotechnology and nanomaterials have been widely developed, the toxicity for health tissues and cells was one of the main therapeutic efficiency-limiting challenges. ${ }^{16}$ Compared with other metal-based NPs such as silver, zinc oxide, and iron oxide, gold nanoparticles (AuNPs) usually show relatively low toxicity, as its core is inert and nontoxic. ${ }^{16,17}$ A variety of methodologies for NP synthesis, including chemical, thermal, electrochemical, and sonochemical pathways, have so far been developed. ${ }^{18}$ In addition, plant extracts, bacteria, and fungi, among others, have been considered as potential materials for the biosynthesis of AuNPs. ${ }^{19}$ Importantly, natural plants used to mediate synthesis have been proven to have a double effect, acting both as reducing and capping agents and then improving the pharmacological activity and stability of AuNPs in a synergistic manner. ${ }^{20}$ The plant-mediated synthesis of metallic NPs is an increasing commercial demand due to its wide applicability in various areas such as electronics, catalysis, chemistry, energy, cosmetics, and medicine. In the current study, we used an extract of Euphrasia officinalis for the green synthesis of AuNPs and investigated its antiinflammatory function.

E. officinalis, commonly known as eyebright, is an important medicinal plant in the genus Euphrasia, belonging to the Orobanchaceae family. It has been widely used in Europe as an anti-inflammatory agent for hay fever, sinusitis, and upper respiratory tract infections, ${ }^{21}$ and especially as an eye lotion to treat and prevent eye disorders such as conjunctivitis, ophthalmia, ocular allergies, and eye fatigue. ${ }^{22,23}$ In our previous study, an ethanol extract of E. officinalis leaf showed the presence of phenolic acids (caffeic acid) and flavonoids (luteolin-glucoside and rutin). ${ }^{24}$ These compounds are known to act as reducing agents and stabilizers in the bioreduction of gold salt. ${ }^{25,26}$ Moreover, it has been reported that E. officinalis extracts have antioxidant, anti-inflammatory, and antimicrobial activities. ${ }^{22,27}$ Considering the biological functions of E. officinalis, we used it to synthesize AuNPs in an ecofriendly and economical way. Once synthesized, the AuNPs 
were thoroughly characterized using many physicochemical techniques. Finally, we investigated the effects of the synthesized E. officinalis-AuNPs (EO-AuNPs) on LPS-induced inflammation in RAW 264.7 murine macrophages.

\section{Materials and methods Materials and chemicals}

LPS (from Escherichia coli 0111:B4), gold (III) chloride trihydrate $\left(\mathrm{HAuCl}_{4} \cdot 3 \mathrm{H}_{2} \mathrm{O}\right), 2$,2-diphenyl-1-picrylhydrazyl, MTT, dimethyl sulfoxide (DMSO), and all other chemicals were purchased from Sigma-Aldrich Chemicals (St Louis, MO, USA). DMEM, FBS, penicillin-streptomycin, and 0.5\% trypsin-ethylenediaminetetraacetic acid were all purchased from Thermo Fisher Scientific (Waltham, MA, USA). All of the other chemicals and reagents used in this study were of reagent-grade quality and available commercially.

\section{Preparation of E. officinalis extract}

The dried leaf of $E$. officinalis was purchased from Mountain Rose Herbs (Eugene, OR, USA). The preparation of E. officinalis leaf extract was performed in our lab as described previously. ${ }^{24}$ First, $10 \mathrm{~g}$ of dried E. officinalis leaf powder was thoroughly suspended in $50 \mathrm{~mL}$ of $95 \%$ ethanol for 24 hours at $37^{\circ} \mathrm{C}$. This procedure was repeated for threetimes, and then the combined extracts were filtered and completely evaporated using a rotary vacuum evaporator at $40^{\circ} \mathrm{C}$ and finally stored at $4{ }^{\circ} \mathrm{C}$. The dried extract was dissolved in sterile water and filtered through a $0.22 \mu \mathrm{m}$ filter before use.

\section{Green synthesis of EO-AuNPs}

For the synthesis of EO-AuNPs, $5 \mathrm{mg}$ of E. officinalis leaf extract was dissolved in $10 \mathrm{~mL}$ of sterile water and passed through a $0.22 \mu \mathrm{m}$ filter before use. Gold salt was added with a final concentration of $1 \mathrm{mM}$ in the reaction mixtures. The reaction mixtures were incubated in a shaking incubator for 3 hours at $200 \mathrm{rpm}$ and $37^{\circ} \mathrm{C}$. A color change was observed visually, indicating the formation of AuNPs in the reaction mixtures. The suspension was first centrifuged at 3,500 rpm for 10 minutes to remove the unreacted plant extract. Next, the biosynthesized NPs were collected by centrifugation at $12,000 \mathrm{rpm}$ for 20 minutes and further purified by continuous washing with sterile distilled water to obtain NPs in pellet form. Finally, the purified NPs were suspended in distilled water or air-dried overnight for further study.

\section{Characterization of EO-AuNPs}

The absorbance spectra of the purified NP suspension were scanned in the wavelength range of 300-800 nm using an ultraviolet-visible light spectrophotometer (UV-vis, Cary 60; Agilent, Santa Clara, CA, USA). The morphology, purity, structure, and elemental distribution of the EO-AuNPs were observed by transmission electron microscopy (TEM), energy-dispersive X-ray spectroscopy (EDX), selected area electron diffraction (SAED), and elemental mapping analysis with a JEM-2100F (JEOL, Tokyo, Japan) instrument operated at $200 \mathrm{kV}$. TEM images were obtained by placing droplets of the purified NPs suspended in water on a carboncoated copper grid and drying them at room temperature before microscopic analysis.

Powder X-ray diffraction (XRD) patterns were obtained using a diffractometer (D8 Advance; Karlsruhe, Bruker, Germany) operating at $40 \mathrm{kV}$ and $40 \mathrm{~mA}$, with $\mathrm{CuK} \alpha$ radiation, a scanning rate of $6^{\circ} / \mathrm{min}$, and a step size of $0.02^{\circ}$ over the $2 \theta$ range of $20^{\circ}-80^{\circ}$. The zeta potential of EO-AuNPs suspended in distilled water was determined using a ZetaPotential Analyzer (ELS-Z2; Otsuka Electronics Co. Ltd., Osaka, Japan) at $25^{\circ} \mathrm{C}$.

Fourier-transform infrared (FTIR) spectra of air-dried EO-AuNPs were acquired by a Spectrum ${ }^{\text {TM }}$ One FTIR Spectrometer (PerkinElmer, Waltham, Massachusetts, USA) from $4,000-450 \mathrm{~cm}^{-1}$ and at a resolution of $4 \mathrm{~cm}^{-1}$ on $\mathrm{KBr}$ pellets. FTIR analysis was employed to identify the possible functional groups of the plant extract capped on the surfaces of the AuNPs.

\section{Cell culture}

Murine macrophages (RAW 264.7) were obtained from the Korean Cell Line Bank (Seoul, Republic of Korea). Cells were cultured in DMEM supplemented with 10\% heatinactivated $\mathrm{FBS}$ and $1 \%$ penicillin-streptomycin at $37^{\circ} \mathrm{C}$ in a $5 \% \mathrm{CO}_{2}$ humidified incubator.

\section{Enhanced dark-field microscopy system}

RAW 264.7 cells were seeded onto $18 \mathrm{~mm}$ coverslips at a density of $1 \times 10^{5}$ cells $/ \mathrm{mL}$ overnight at $37^{\circ} \mathrm{C}$ in a $5 \% \mathrm{CO}_{2}$ humidified incubator, and were then treated with $80 \mu \mathrm{g} / \mathrm{mL}$ of EO-AuNPs. After 3 hours of incubation, the cell medium was removed, and the cells were rinsed three times with PBS to remove the unbound NPs. The coverslips were placed on the slides and sealed using clear fingernail polish. The EO-AuNPs associated with cells were then observed via resonant light scattering using a lab-made wavelength-dependent enhanced dark-field microscopic system, which was an enhanced dark-field (EDF) illumination system (CytoViva Inc., Auburn, AL, USA) attached to an upright Olympus BX51 microscope (Olympus Optical Co., Ltd., Tokyo, Japan). ${ }^{28}$ 


\section{Transmission electron microscopy analysis}

RAW 264.7 cells were seeded at a density of $1 \times 10^{5}$ cells/well in a six-well plate overnight at $37^{\circ} \mathrm{C}$ with $5 \% \mathrm{CO}_{2}$ and then were treated with EO-AuNPs ( 40 and $80 \mu \mathrm{g} / \mathrm{mL}$ ). After 3 hours of incubation, the cell media were discarded and the cells were rinsed three times with PBS to remove the unbound NPs. Cell pellets were fixed with $2.5 \%$ glutaraldehyde for 8 hours, post-fixed with $1 \%$ osmium tetroxide for 2 hours, and dehydrated through an ethanol series $(50 \%, 70 \%$, and $90 \%$ for 15 minutes each, and $100 \%$ for 15 minutes twice). The samples were embedded in propylene oxide: Epon (2:1, $50^{\circ} \mathrm{C}$ for 1 day and $60^{\circ} \mathrm{C}$ for 2 days). Ultrathin sections $(70 \mathrm{~nm}$ ) were cut using an ultramicrotome (Leica EM UC7, Wetzlar, Germany), placed on the grids, stained with $3 \%$ uranyl acetate and lead citrate, and imaged using an $80 \mathrm{kV}$ JEM-1010 TEM (JEOl, Tokyo, Japan).

\section{Cell viability assay}

The cytotoxicity of EO-AuNPs against RAW 264.7 macrophages was analyzed by the MTT assay. RAW 264.7 cells were seeded at a density of $1 \times 10^{5}$ cells per well in a 96-well culture plate (containing $100 \mu \mathrm{L}$ of culture medium) for 24 hours of incubation. When they reached $90 \%$ confluence, cells were treated with various concentrations of EO-AuNPs (10-100 $\mu \mathrm{g} / \mathrm{mL})$. After 24 hours of incubation, $100 \mu \mathrm{L}$ of MTT solution at a final concentration of $0.5 \mathrm{mg} / \mathrm{mL}$ was added to each well and further incubated for 3 hours. Finally, $100 \mu \mathrm{L}$ of DMSO was added to dissolve the formazan crystals. The absorbance of each well was measured at $570 \mathrm{~nm}$ using a microplate reader (Filter Max F5; Molecular Devices, San Francisco, CA, USA). Blank values were subtracted from experimental values.

\section{Nitric oxide analysis}

RAW 264.7 cells were seeded at a density of $5 \times 10^{4}$ cells/well in a 96-well plate (containing $200 \mu \mathrm{L}$ of culture medium) in triplicate and then pre-incubated with various concentrations (10-100 $\mu \mathrm{g} / \mathrm{mL})$ of EO-AuNPs before stimulation with or without LPS $(1 \mu \mathrm{g} / \mathrm{mL})$ for 24 hours. Then, $100 \mu \mathrm{L}$ of supernatant of cultured medium was transferred to a corresponding well in another plate and mixed with $100 \mu \mathrm{L}$ of Griess reagent. After 10 minutes of incubation at room temperature, the absorbance was measured at $570 \mathrm{~nm}$. Finally, the concentration of nitrite was calculated from a standard sodium curve.

\section{Analysis of pro-inflammatory cytokine production}

RAW 264.7 macrophages $\left(1 \times 10^{5}\right.$ cells/well) were seeded in 24-well plates. The cells were pretreated with various concentrations of EO-AuNPs for 1 hour, followed by stimulation with $1 \mu \mathrm{g} / \mathrm{mL}$ LPS for 6 hours. Subsequently, supernatants were collected from the cell media to measure the production of TNF- $\alpha$, IL- $1 \beta$, and IL- 6 using an ELISA according to the manufacturer's instructions (R\&D Systems, Minneapolis, MN, USA).

\section{Reverse transcription-PCR (RT-PCR) analysis}

Total RNA was extracted from RAW 264.7 cells using a Trizol reagent kit (Thermo Fisher Scientific), carefully following the manufacturer's instructions. First, $2 \mu \mathrm{g}$ of total RNA was used as a template to make the first strand of cDNA using the AccuPower RT PreMix (Bioneer, Daejeon, Republic of Korea) and then $1 \mu \mathrm{L}$ of the cDNA mixture was used for enzymatic amplification. The PCR was performed using the AccuPower HotStart PCR PreMix (Bioneer). The primers used in this study were as follows: iNOS, forward 5'-CCCTTCCGAAGTTTCTGGCAGCAGC- ${ }^{\prime}$ ' and reverse 5'-GGCTGTCAGAGAGCCTCGTGGCTTTGG-3'; and glyceraldehyde-3-phosphate dehydrogenase (GAPDH), forward 5'-ACCACAGTCCATGCCATCAC- ${ }^{\prime}$ and reverse 5'-CCACCACCCTGTTGCTGTAG-3'. The PCR products were separated by performing $2.0 \%$ agarose gel electrophoresis, stained with ethidium bromide, and detected by using UV transilluminator. The housekeeping gene GAPDH was used as an internal control. All the real-time experiments were performed in triplicate, and statistical analysis was carried out using Student's $t$-tests.

\section{Western blot analysis}

RAW 264.7 cells at $5 \times 10^{5}$ cells/well were plated in $60 \mathrm{~mm}$ dishes for 24 hours and then incubated with various concentrations $(10-100 \mu \mathrm{g} / \mathrm{mL})$ of EO-AuNPs and LPS $(1 \mu \mathrm{g} / \mathrm{mL})$ for 6 hours. After being washed with PBS, cell pellets were collected by centrifugation and lysed using cell RIPA lysis buffer for 1 hour. The cell lysates were centrifuged at $12,000 \mathrm{rpm}$ for 20 minutes at $4^{\circ} \mathrm{C}$, and the protein content was quantified using the Bradford reagent (Sigma-Aldrich Co.). Equal amounts $(50 \mu \mathrm{g})$ of total protein were loaded in $10 \%$ SDS-PAGE and transferred to nitrocellulose membranes. Membranes were blocked with $5 \%$ skim milk or BSA at room temperature for 1 hour and then incubated with primary antibodies against iNOS, I $\mathrm{B} \alpha, \mathrm{p}-\mathrm{I} \kappa \mathrm{B} \alpha, \mathrm{NF}-\kappa \mathrm{B}$ p65, JAK1, p-JAK1, STAT1, p-STAT1, STAT3, p-STAT3, $\beta$-actin, and histone for overnight at $4^{\circ} \mathrm{C}$. After being washed three times with Tris-buffered saline-Tween $20(0.1 \%)$, the membranes were incubated with respective secondary antibodies conjugated with horseradish peroxidase (Santa Cruz 
Biotechnology, Inc., Santa Cruz, CA, USA) for 1 hour. The immunoreactive bands were visualized with an enhanced chemiluminescence detection system (Fujifilm, LAS-4000, Tokyo, Japan) and normalized to the $\beta$-actin expression on the same membrane.

\section{Statistical analysis}

Experimental data are reported as mean \pm standard errors of the mean. Statistical analysis was performed using GraphPad Prism 6 (GraphPad Software, Inc., La Jolla, CA, USA). Statistical significance was evaluated using one-way ANOVA followed by Dunnett's multiple comparison test. $P<0.05, P<0.01$, and $P<0.001$ were considered to be statistically significant.

\section{Results}

\section{Synthesis and characterization of EO-AuNPs}

The ethanol extract of E. officinalis leaf exhibited the ability of reducing $\mathrm{HAuCl}_{4} \cdot 3 \mathrm{H}_{2} \mathrm{O}$ to result in the synthesis of AuNPs. UV-vis spectroscopy over the range of 350-800 nm resulted in a strong absorption peak at $540 \mathrm{~nm}$, which corresponded to the surface plasmon resonance (SPR) band of the formed AuNPs (Figure 1A). In addition, a visible color change was also observed in the reaction mixture from light yellow to deep purple. These results clearly confirmed the synthesis of AuNPs from E. officinalis leaf extract.

A TEM image of EO-AuNPs is shown in Figure 1B, which reveals a majority of spherical or hexagonal shapes with lattice fringes and a few triangular-shaped NPs with sizes varying from 5 to $30 \mathrm{~nm}$. Elemental mapping indicated the distribution of elemental gold in the bioreduced NPs (Figure 2A and B). The distribution of gold was visible in the electron image, suggesting that gold was the predominant element in the NPs. EDX analysis of EOAuNPs (Figure 2C) showed a strong optical absorption peak at $2.3 \mathrm{keV}$, which corresponded to the characteristic peak of elemental gold. The other metal group recorded at $8 \mathrm{keV}$ corresponded to the copper grid utilized for study. The SAED pattern indicated the diffraction pattern of multiple particles and metallic nature of the synthesized EP-AuNPs (Figure 2D). In addition, similar results were
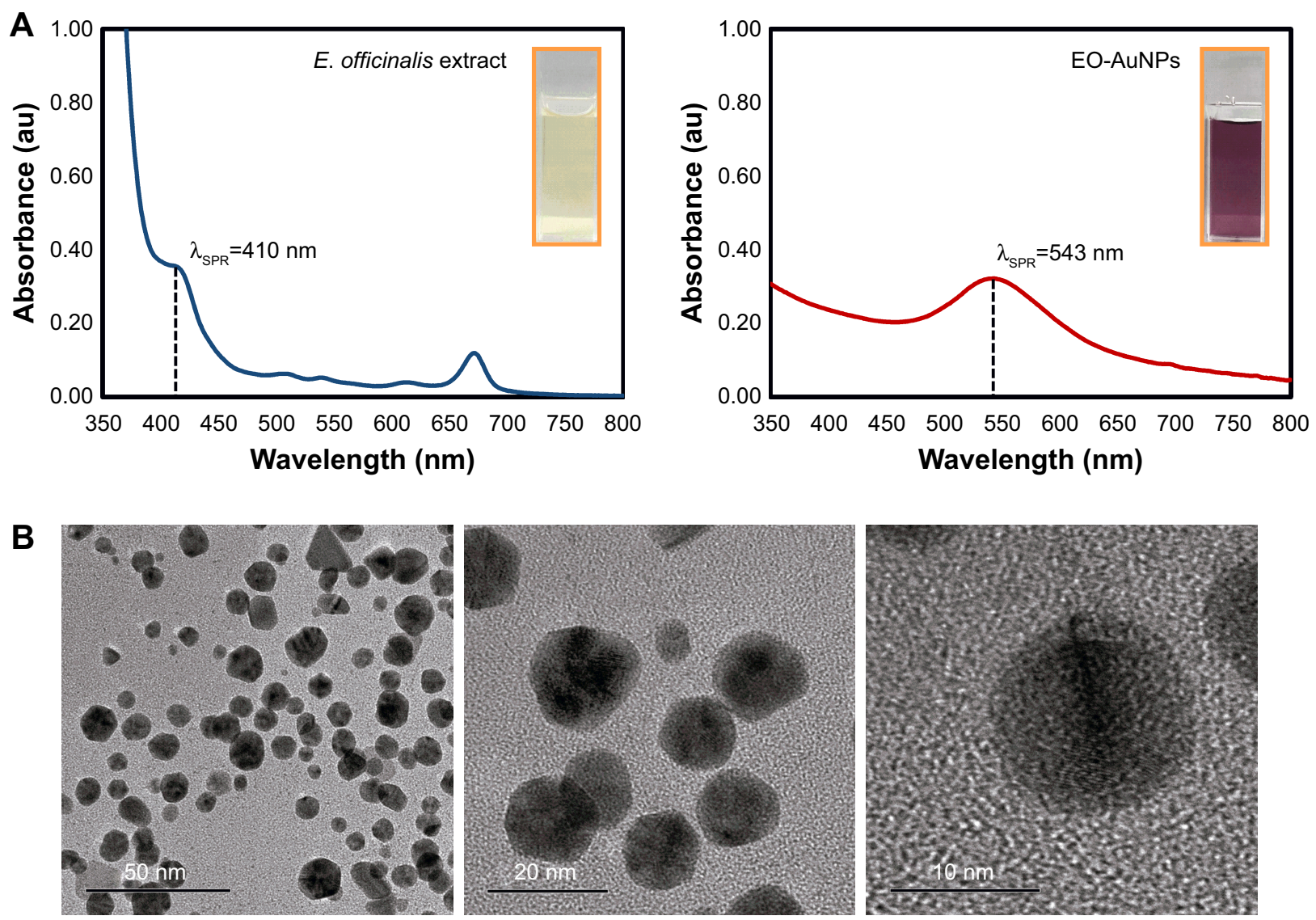

Figure I (A) UV-vis spectra and (B) TEM images of EO-AuNPs.

Abbreviations: UV-vis, ultraviolet-visible; E. officinalis, Euphrasia officinalis; EO-AuNPs, E. officinalis-gold nanoparticles; TEM, transmission electron microscopy; SPR, surface plasmon resonance. 

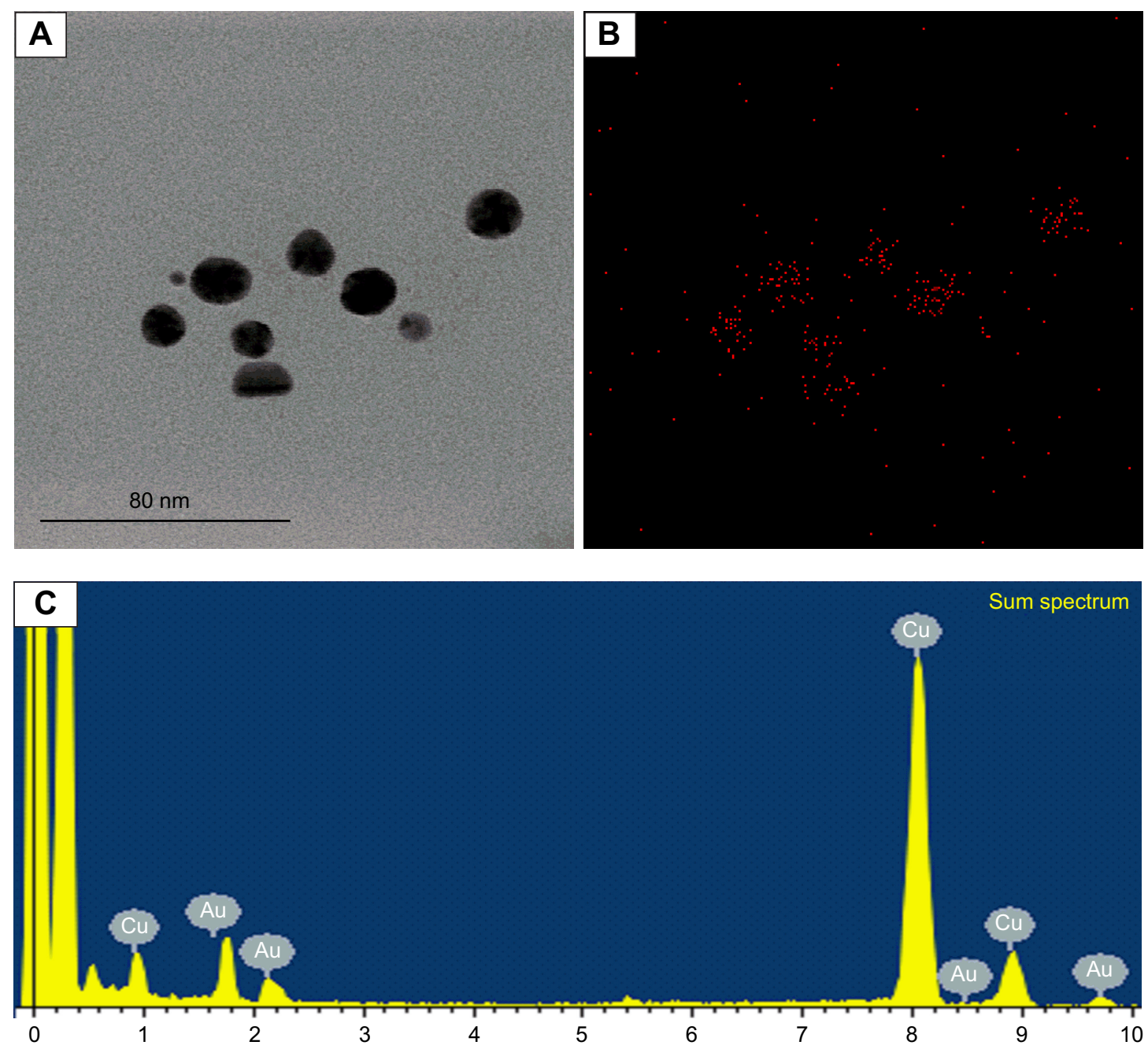

Full scale 1,449 cts cursor: 0.000
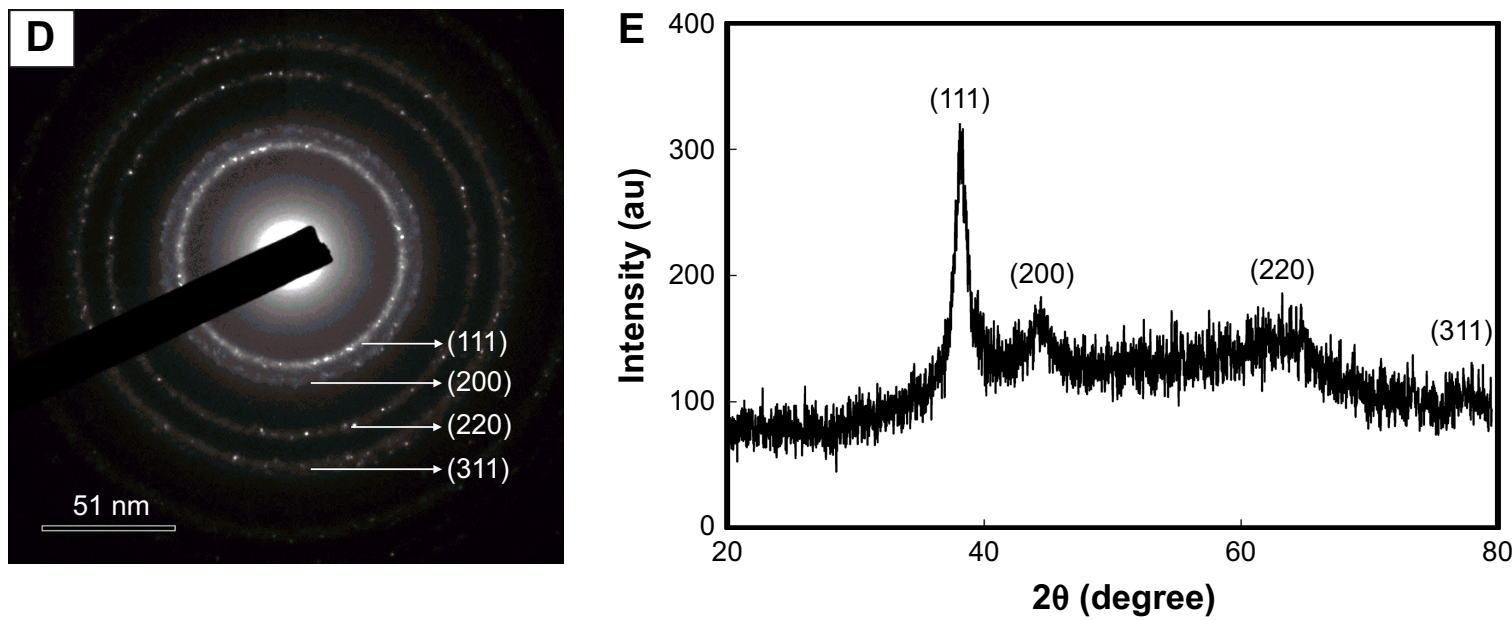

Figure 2 (A and B) Elemental mapping, (C) EDX spectrum, (D) XRD, and (E) SAED pattern of EO-AuNPs.

Abbreviations: EDX, energy-dispersive X-ray; XRD, X-ray diffraction; SAED, selected area electron diffraction; EO-AuNPs, Euphrasia officinalis-gold nanoparticles.

documented in the XRD analysis. As shown in Figure 2E, four characteristic peaks of gold were indexed to the (111), (200), (220), and (311) lattice planes of Bragg's reflection, and four diffraction peaks were displayed at the $2 \theta$ values of $38.11^{\circ}, 45.15^{\circ}, 64.65^{\circ}$, and $77.93^{\circ}$. The zeta-potential value of EO-AuNPs revealed the stability of NPs in suspension form with a negative surface net charge of $-39.9 \mathrm{mV}$ (data not shown). 
The FTIR spectra of the E. officinalis leaf extract and EO-AuNPs revealed bands at 3,326.32 and 3,385.65 $\mathrm{cm}^{-1}$ corresponding to the $\mathrm{O}-\mathrm{H}$ stretching, those at 2,922.84, $2,920.18,2,852.79$, and $2,850.47 \mathrm{~cm}^{-1}$ corresponding to the $\mathrm{C}-\mathrm{H}$ stretching, at $1,735.49-1,508.68 \mathrm{~cm}^{-1}$ corresponding to the $\mathrm{C}=\mathrm{O}$ and aromatic $\mathrm{C}=\mathrm{C}$ double-bond functional groups, in the range from $1,458.79$ to $1,024.28 \mathrm{~cm}^{-1}$ corresponding to aromatic $\mathrm{C}-\mathrm{C}$ groups and $\mathrm{C}-\mathrm{O}$ functional groups, and those at $810.94,713.20$, and $722.12 \mathrm{~cm}^{-1}$ corresponding to the deformation vibration of $\mathrm{C}-\mathrm{H}$ bonds in the phenolic rings (Figure 3). ${ }^{29-31}$

\section{Evaluation of nanoparticle uptake and intracellular localization}

To visualize the NPs' uptake ability, macrophages were incubated with EO-AuNPs for two different time durations ( 5 minutes and 3 hours). We first performed bright-field microscopy to locate the cells, and then switched to EDF microscopy for analysis. As shown in Figure 4, the uptake of NPs was very fast, starting at 5 minutes after being added to the RAW 264.7 macrophages. After 3 hours of incubation, there appeared to be better uptake that was intracellularly localized, likely in the form of aggregates, as shown by the bright white spots inside the macrophages.

Further evidence supporting the intracellular localization of the EO-AuNPs was acquired via TEM. Previous studies have demonstrated the endocytotic uptake of the NPs in both monocytes and macrophages regarding both the adsorptive step on the plasma membrane and the further localization in the lysosomes. ${ }^{32}$ Our findings also suggest that clustered EO-AuNPs were detected outside of the cell membrane and also within the intracellular compartments resembling phagosomes and lysosomes (Figure 5).

\section{Effect of EO-AuNPs on cell viability}

The potential cytotoxicity of EO-AuNPs in RAW 264.7 macrophages was investigated by MTT assay. EO-AuNPs were evaluated at concentrations ranging from 20 to $100 \mu \mathrm{g} / \mathrm{mL}$.
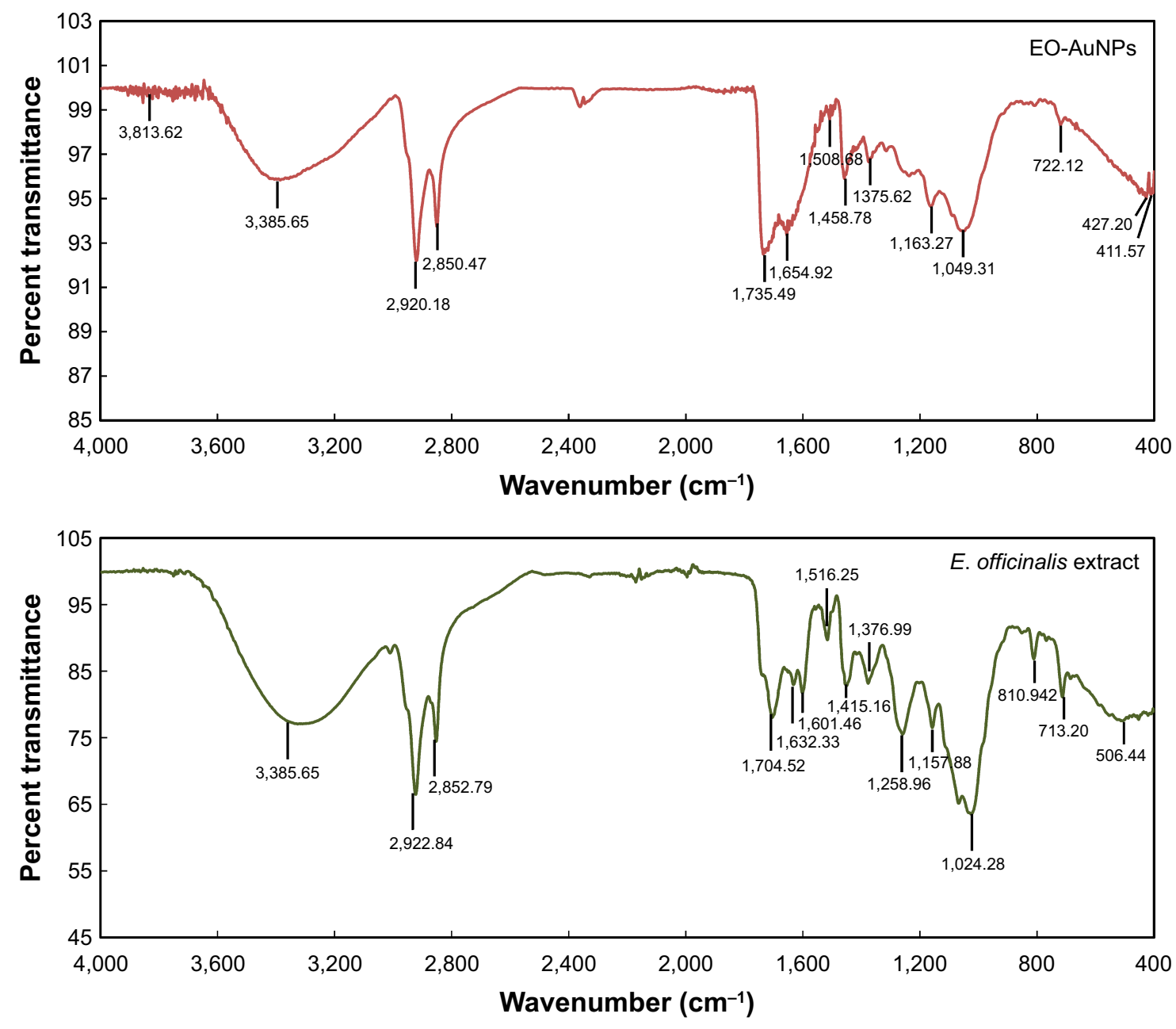

Figure 3 FTIR analysis of synthesized EO-AuNPs and plant extract of $E$. officinalis.

Abbreviations: FTIR, fourier-transform infrared; E. officinalis, Euphrasia officinalis; EO-AuNPs, E. officinalis-gold nanoparticles. 

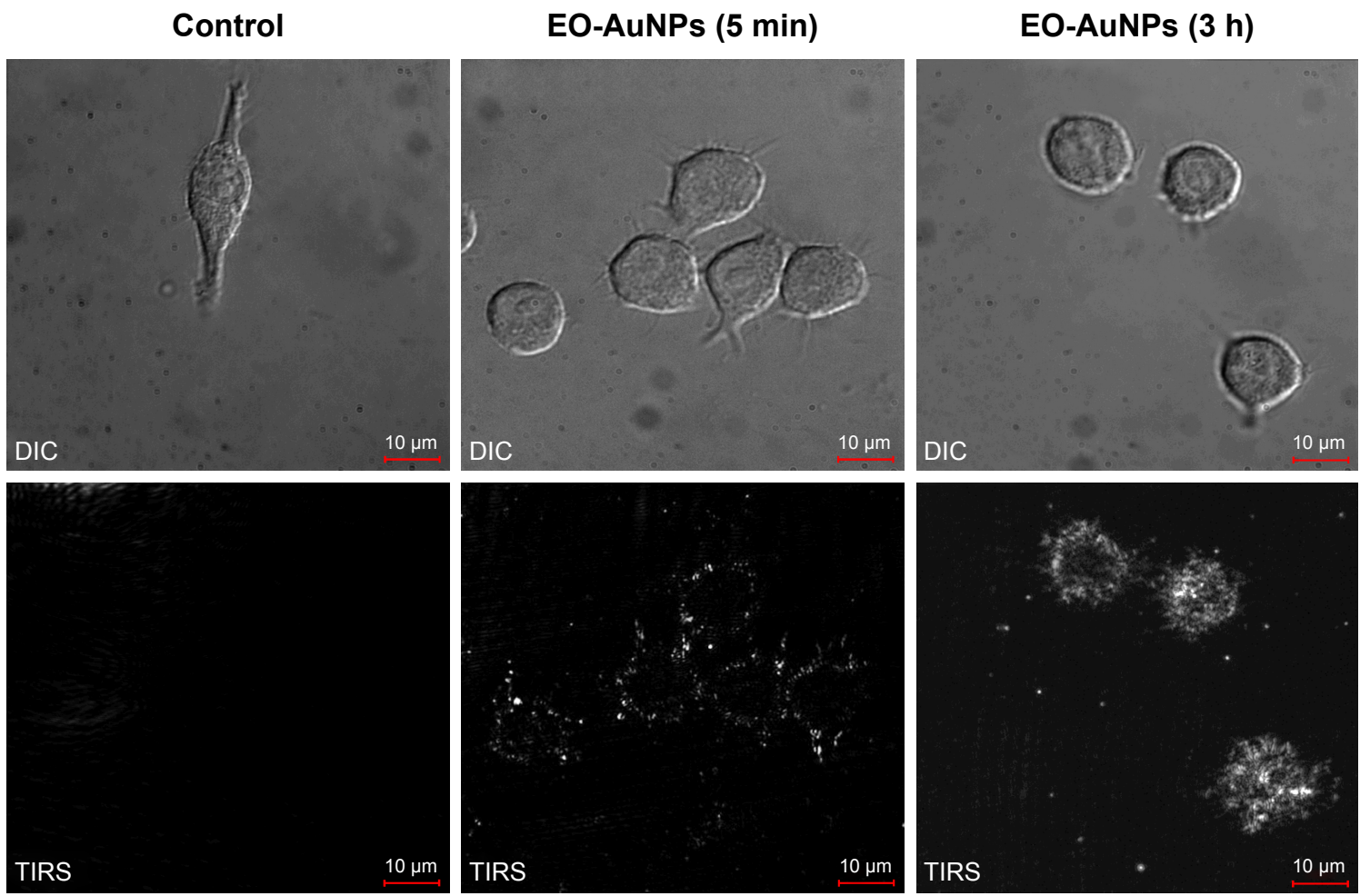

Figure 4 Uptake of EO-AuNPs by RAW 264.7 cells observed with an enhanced dark-field (EDF) microscopy. Cells were incubated with EO-AuNPs (80 $\mu$ g/mL) for 5 minutes and 3 hours and then were observed by EDF illumination system. The bright white spots inside the macrophages represent the aggregation of EO-AuNPs.

Abbreviations: DIC, differential interference contrast; TIRS, thermal infrared sensor; EO-AuNPs, Euphrasia officinalis-gold nanoparticles.

As shown in Figure 6A, EO-AuNPs did not exhibit cytotoxicity against RAW 264.7 cells at the concentrations from 20 to $80 \mu \mathrm{g} / \mathrm{mL}$. However, $25.5 \%$ cell death was caused at the concentration of $100 \mu \mathrm{g} / \mathrm{mL}$.

\section{Effect of EO-AuNPs on NO production}

To determine whether EO-AuNPs could inhibit NO production in LPS-stimulated RAW 264.7 cells, we determined the levels of nitrite, which is a stable product of NO metabolism, in the culture media using the Griess reagent. Exposure to LPS $(1 \mu \mathrm{g} / \mathrm{mL})$ for 24 hours markedly induced excess release of NO (Figure 6B). The increase of NO production was significantly suppressed by EO-AuNPs in a concentration-dependent manner. However, given that a $100 \mu \mathrm{g} / \mathrm{mL}$ concentration of EO-AuNPs caused cytotoxicity in RAW 264.7 cells, EO-AuNPs concentrations from 40 to
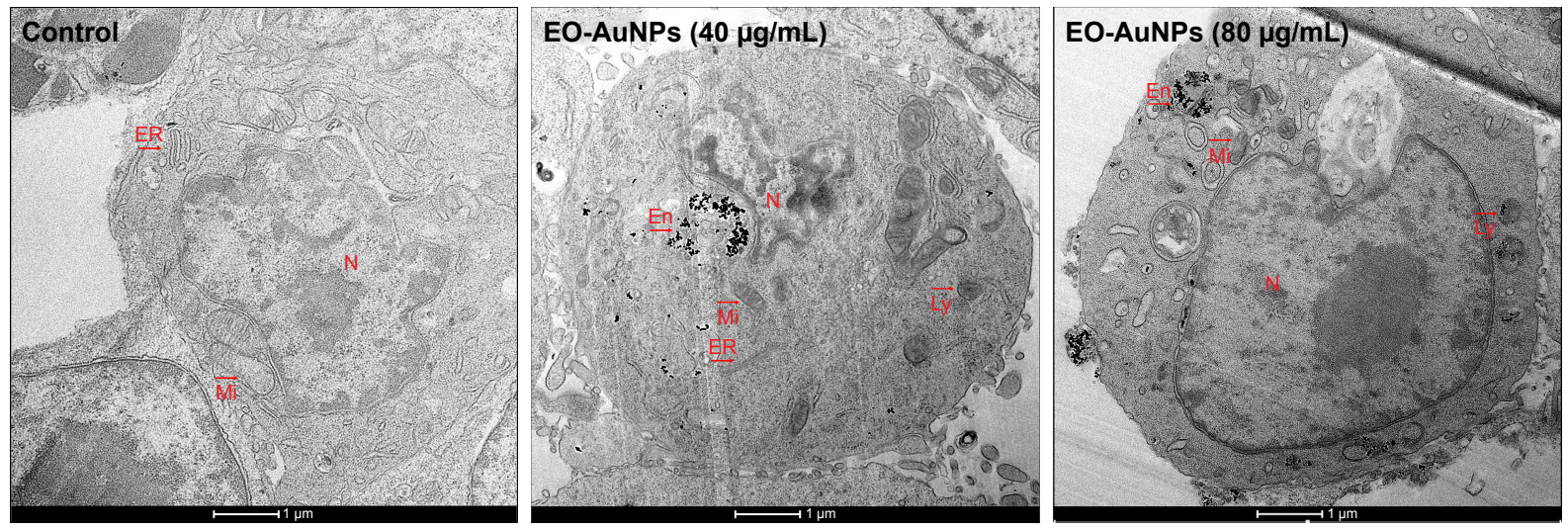

Figure 5 Intracellular localization of EO-AuNPs in RAW 264.7 cells observed by a transmission electron microscopy (TEM). Cells were treated with EO-AuNPs (40 and $80 \mu \mathrm{g} / \mathrm{mL}$ ) for 3 hours and then were fixed and examined by TEM (scale bar $=1 \mu \mathrm{m}$ ). EO-AuNPs are distributed in the membrane-bound compartments, resembling endosomes or lysosomes.

Abbreviations: N, nucleus; Mi, mitochondria; ER, endoplasmic reticulum; En, endosome; Ly, lysosome; EO-AuNPs, Euphrasia officinalis-gold nanoparticles. 
A

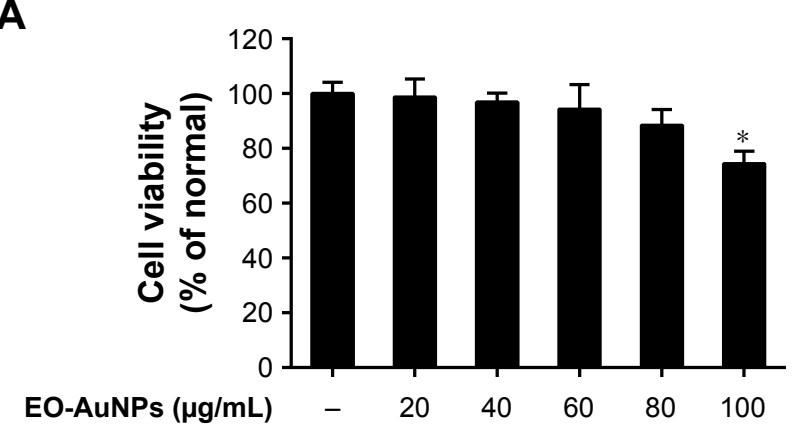

B

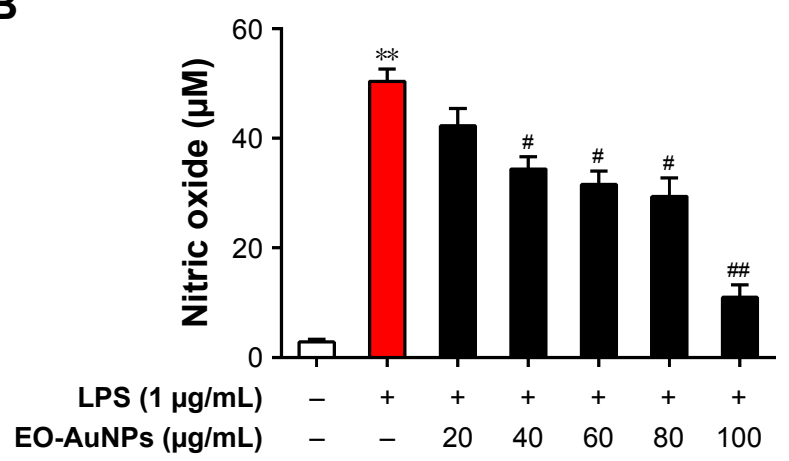

C

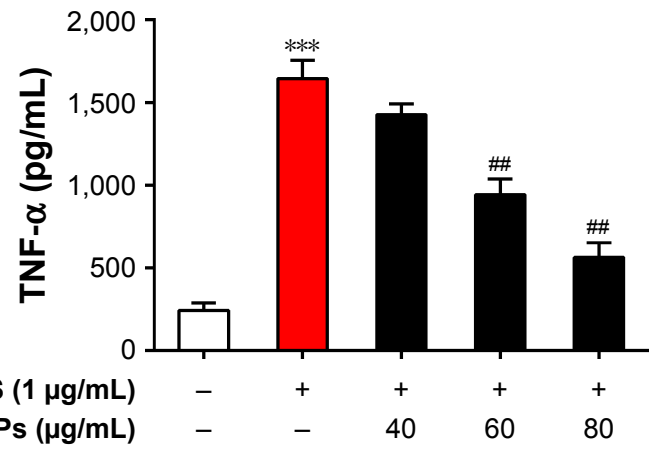

D

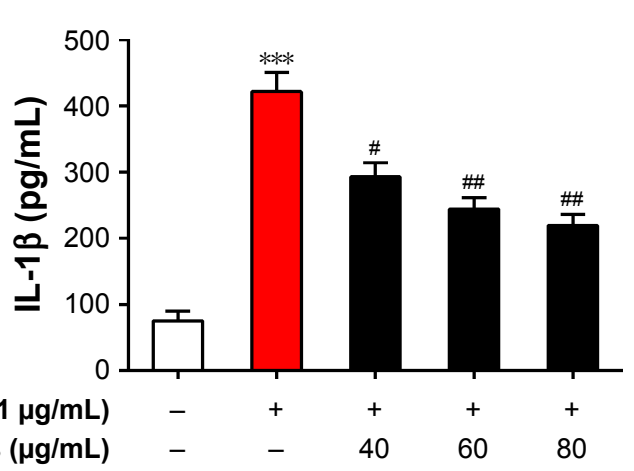

$\mathbf{E}$

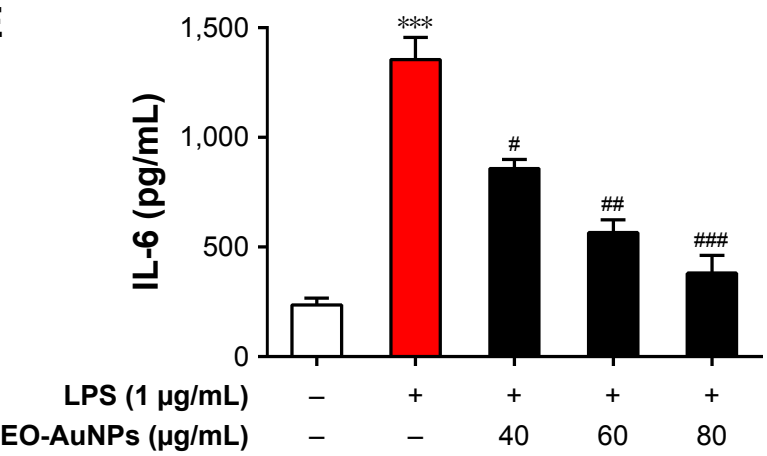

Figure 6 Effect of EO-AuNPs on LPS-induced inflammatory mediators production in RAW 264.7 cells. (A) Cell viability was measured by MTT assay. (B) The concentration of NO in medium was measured by Griess method. (C-E) The production of TNF- $\alpha$, IL-I $\beta$, and IL- 6 in medium was measured using ELISA kits. Data are representative of three independent experiments and values are shown as mean \pm SEM. $* P<0.05, * * P<0.0$ I, ${ }^{* * *} P<0.00$ I compared to non-treated control. ${ }^{\#} P<0.05$, ${ }^{\#} P<0.0$ I, ${ }^{\# \# P<0.001}$ compared to the LPS control.

Abbreviations: TNF- $\alpha$, tumor necrosis factor- $\alpha$; EO-AuNPs, Euphrasia officinalis-gold nanoparticles; LPS, lipopolysaccharide; NO, nitric oxide; SEM, standard error of the mean.

$80 \mu \mathrm{g} / \mathrm{mL}$ exhibited significant inhibition of LPS-induced NO production without obvious toxicity.

\section{Effects of EO-AuNPs on the production of pro-inflammatory cytokines}

Pro-inflammatory cytokines, such as TNF- $\alpha$, IL-1 $\beta$, and IL-6, are of great importance in the inflammatory process. To further estimate the effects of EO-AuNPs on inflammation, the production of these cytokines in LPS-treated macrophages was measured by ELISA. As shown in Figure 6C-E, the LPS-induced TNF- $\alpha$, IL-1 $\beta$, and IL- 6 releases were significantly blocked by the EO-AuNPs in a dose-dependent manner.

\section{Effects of EO-AuNPs on iNOS gene and protein expression}

To determine whether the anti-inflammatory effects of EO-AuNPs are involved in the suppression of NO, the production of iNOS induced by LPS in RAW 264.7 cells was measured by RT-PCR and Western blot methods. The RAW 264.7 cells were treated with or without various concentrations $(40,60$, and $80 \mu \mathrm{g} / \mathrm{mL})$ of EO-AuNPs and $1 \mu \mathrm{g} / \mathrm{mL}$ 
A

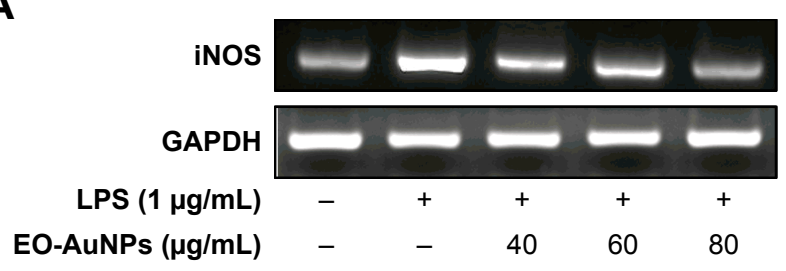

B

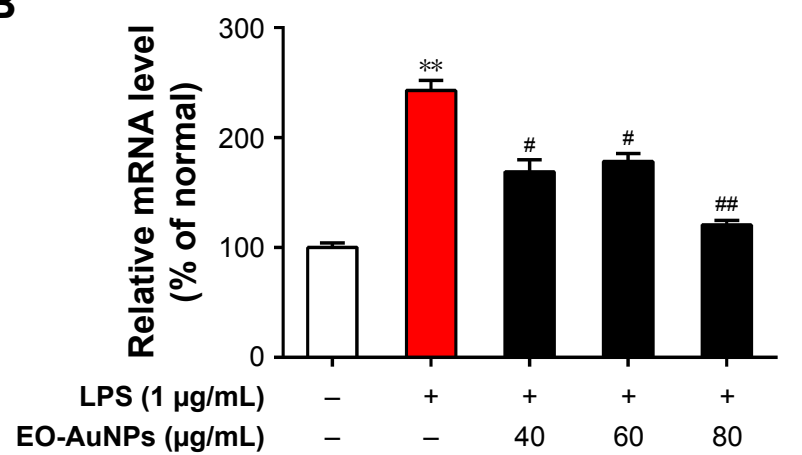

C

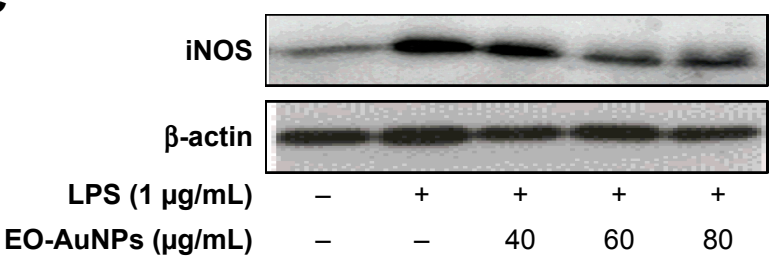

D

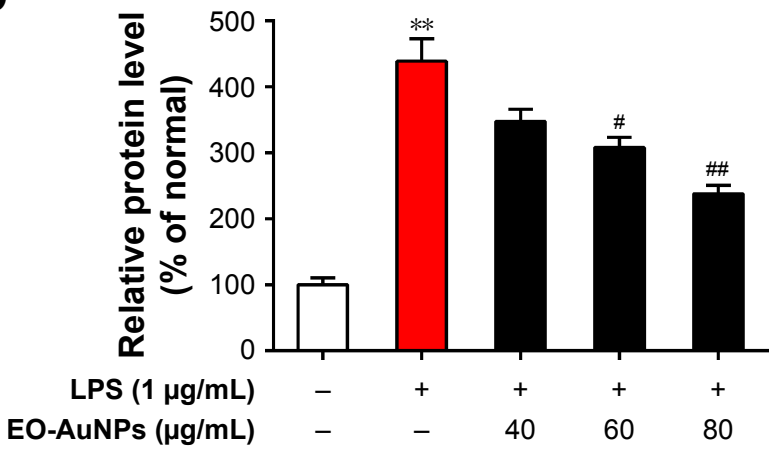

Figure 7 Effect of EO-AuNPs on LPS-induced iNOS expression in RAW 264.7 cells. (A and B) mRNA expression of iNOS was determined by RT-PCR analysis and normalized to the corresponding value of GAPDH. (C and D) Protein expression of iNOS was determined by Western blot analysis and normalized to the corresponding value of $\beta$-actin. Densitometry data are expressed as percentage relative to the non-treated control and shown as mean \pm SEM. $* * P<0.01$ compared to the non-treated control. ${ }^{\# P<0.05, ~}{ }^{\# P}<0.01$ compared to the LPS control.

Abbreviations: iNOS, inducible nitric oxide synthase; EO-AuNPs, Euphrasia officinalis-gold nanoparticles; LPS, lipopolysaccharide; RT-PCR, reverse transcription-PCR; SEM, standard error of the mean; GAPDH, glyceraldehyde-3-phosphate dehydrogenase.

of LPS for 24 hours. Significant increases in the iNOS mRNA (Figure 7A and B) and protein (Figure 7C and D) were shown by LPS-stimulated RAW 264.7 macrophages. However, EO-AuNPs obviously suppressed the expression of the iNOS gene and protein in a dose-dependent manner, demonstrating the inhibitory effect of EO-AuNPs on iNOS transcriptional events in LPS-stimulated macrophages.

\section{Effects of EO-AuNPs on the NF-kB signaling pathway}

Under inactive conditions, the NF- $\mathrm{KB}$ dimer is bound to its inhibitory protein $\mathrm{I} \kappa \mathrm{B} \alpha$ in the cytoplasm. Once stimulated by LPS, the phosphorylated I $\mathrm{KB} \alpha$ is ubiquitinated and degraded, resulting in the nuclear translocation of NF- $\kappa B$, which leads to the transcription of inflammatory genes such as TNF- $\alpha$, IL-1 $\beta$, and IL- $6 .{ }^{33}$ In the present study, RAW 264.7 cells were incubated with EO-AuNPs at various doses for 1 hour, followed by LPS $(1 \mu \mathrm{g} / \mathrm{mL})$ treatment for 4 hours. As shown in Figure 8A and B, pretreatment with EO-AuNPs distinctly blocked the LPS-induced upregulation of the phosphorylation and degradation of the Iא $\mathrm{B} \alpha$ protein. In addition, we found that LPS treatment showed an enhancement of nuclear NF- $\mathrm{\kappa B}$ and a reduction of cytosolic NF- $\mathrm{KB}$ (Figure $8 \mathrm{C}$ and D). However, pretreatment with EO-AuNPs reduced the protein expression of the nuclear
NF- $\kappa \mathrm{B}$ p65 subunit. Therefore, the results demonstrated that EO-AuNPs significantly inhibited the translocation of $\mathrm{NF}-\kappa \mathrm{B}$ from the cytoplasm to the nucleus in LPS-stimulated RAW 264.7 cells.

\section{Effects of EO-AuNPs on the JAK/STAT signaling pathway}

The LPS-stimulated activation of JAK/STAT signaling plays an important role in inflammatory responses. We therefore determined several crucial transcription factors to investigate whether EO-AuNPs suppressed the activation of JAK/STAT signaling in LPS-stimulated RAW 264.7 macrophages. As shown in Figure 9, EO-AuNPs dramatically attenuated the upregulation of the phosphorylation of STAT1 and STAT3 in a dose-dependent manner. Moreover, the LPS-induced phosphorylation of JAK1 was decreased by the EO-AuNPs.

\section{Discussion}

AuNPs are extensively used in the biomedical field to treat various medical diseases such as cancer, inflammatory diseases, and immune system disorders, owing to their unique physicochemical and optical properties. Rapid biosynthesis of NPs was observed in different shapes (twinning, mixed structures, and dislocations), and sizes of NPs were increased by using high concentrations of plant extract. ${ }^{34}$ 
A

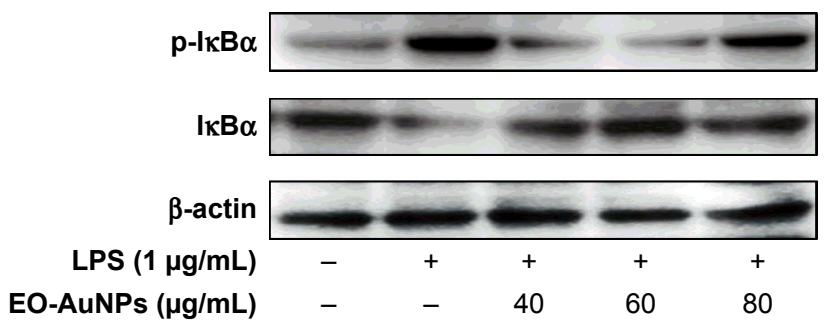

C

Cytosolic NF-kB

Cytosolic $\beta$-actin

Nuclear NF-kB

Nuclear histone

LPS $(1 \mu \mathrm{g} / \mathrm{mL})$

EO-AuNPs $(\mu \mathrm{g} / \mathrm{mL})$
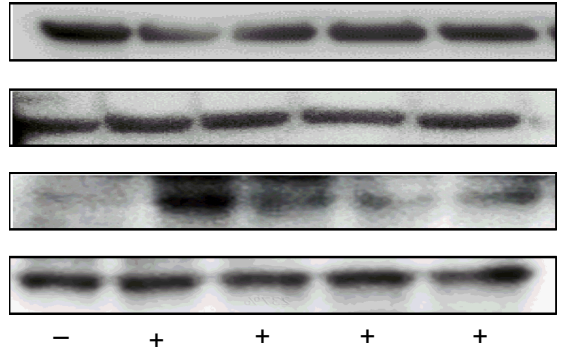

\begin{tabular}{l}
$-\quad 40 \quad 60 \quad 80$ \\
\hline
\end{tabular}
B

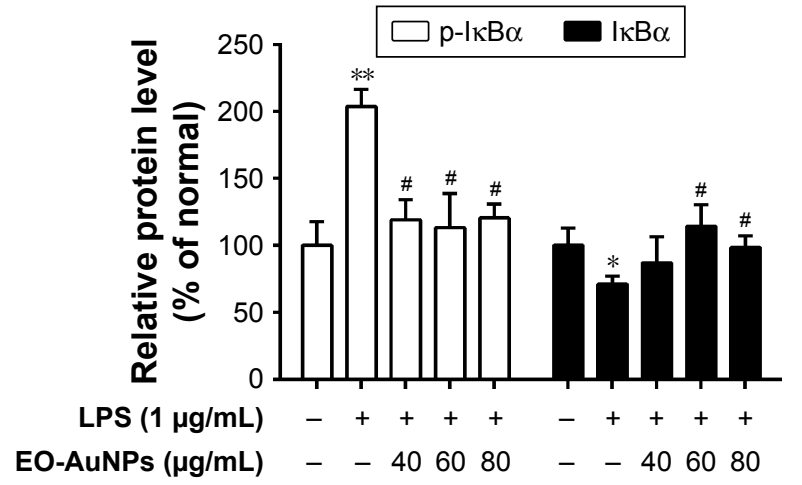

D

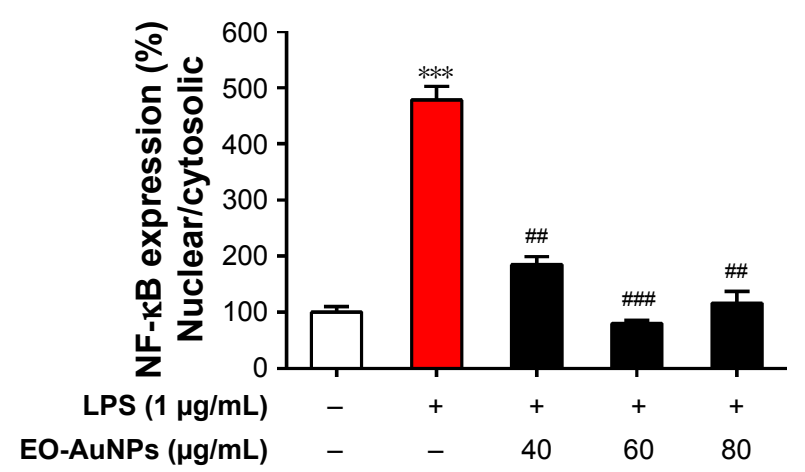

Figure 8 Effect of EO-AuNPs on NF- $\kappa B$ signaling-related protein expression in RAW 264.7 cells. (A and C) The proteins of cytosolic $p-I \kappa B \alpha$, I $\kappa B \alpha$, and nuclear NF- $\kappa B$ p65 in LPS-stimulated RAW 267.4 cells were measured by Western blot analysis. The band intensities for (B and $\mathbf{D}) \mathrm{p}$-I $\mathrm{kB} \alpha$, I $\mathrm{kB} \alpha$, and nuclear NF- $\kappa B$ p65 were quantified and normalized to the corresponding value of $\beta$-actin and histone. Densitometry data are expressed as percentage relative to the non-treated control and shown as mean \pm SEM. $* P<0.05, * * P<0.01$, $* * * P<0.001$ compared to the non-treated control. ${ }^{\#} P<0.05,{ }^{\#} P<0.01,{ }^{\# \# P<0.00 I}$ compared to the LPS control.

Abbreviations: NF- $\kappa B$, nuclear factor kappa-B; $\mathrm{P}-\mathrm{I} \mathrm{KB} \alpha$, phosphorylated inhibitor kappa B-alpha; EO-AuNPs, Euphrasia officinalis-gold nanoparticles; LPS, lipopolysaccharide; SEM, standard error of the mean.

The ease of AuNP functionalization provides a versatile platform, and bioconjugates of AuNPs have also become promising candidates in the design of novel biomaterials for the investigation of biological systems. ${ }^{35}$ AuNPs have anti-inflammatory properties through their ability to hinder the expression of inflammatory reactions; recently, the anti-inflammatory effects of AuNPs have been reported in LPS-activated murine macrophage cells, ${ }^{36}$ a rat alcoholmethamphetamine-induced liver injury model, ${ }^{37}$ a mesentery microcirculation model, and a mouse high-fat diet-induced obesity model.$^{38}$ Crucially, these AuNPs were synthesized using naturally occurring bioactive compounds or extracts of medicinal plants as reductants, which have the advantages of reducing toxicity and improving biocompatibility and pharmacological activity. NPs can be synthesized by several chemical and physical methods, but the use of such methods is harmful in one way or another. The photosynthesis of NPs is emerging as the intersection of nanotechnology and biotechnology. Due to a growing need to develop environmentally benign technologies in material synthesis, it has received increased attention. In the present study, we synthesized
EO-AuNPs using an ethanol extract of E. officinalis as a green reductant. It has been previously suggested that once the AuNPs are synthesized in a reaction mixture, the visual color changes to a ruby red or deep purple due to the SPR. ${ }^{39}$ The reaction mixture was visually detected by the color change from light yellow to deep purple, clearly indicating that the ethanol extract of E. officinalis had the capacity to reduce $\mathrm{HAuCl}_{4} \cdot 3 \mathrm{H}_{2} \mathrm{O}$ to synthesize the AuNPs. Next, the particle size, shape, and crystalline nature of the synthesized EO-AuNPs were characterized using UV-vis spectroscopy, TEM, EDX, XRD, and FTIR analyses. As shown in the UV-vis absorption spectra of the reaction mixtures, there was a disappearance of the extract peak at $\lambda_{\max }=410 \mathrm{~nm}$ and the appearance of a new peak at $\lambda_{\max }=540 \mathrm{~nm}$, which corresponds to the characteristic SPR phenomena of AuNPs. ${ }^{40}$ TEM showed particles about $5-30 \mathrm{~nm}$ in size and surface morphologies with spherical, hexagonal, and triangularshaped gold NPs, and these unique features have also been reported previously. ${ }^{41}$ EDX and XRD analyses also confirmed the presence of AuNPs and their typical metallic gold nanocrystalline structural patterns. The intense peaks present in 
A

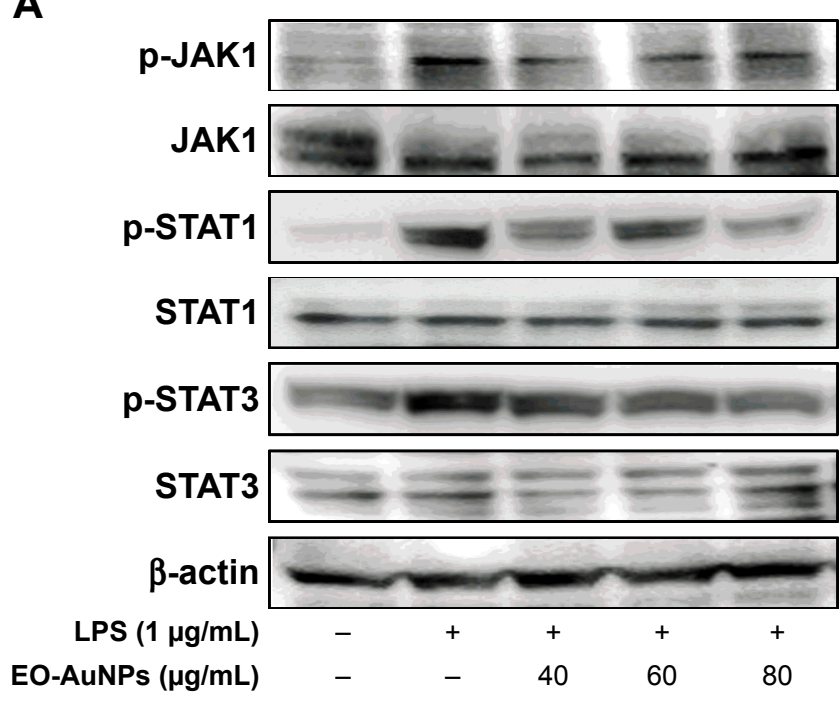

B

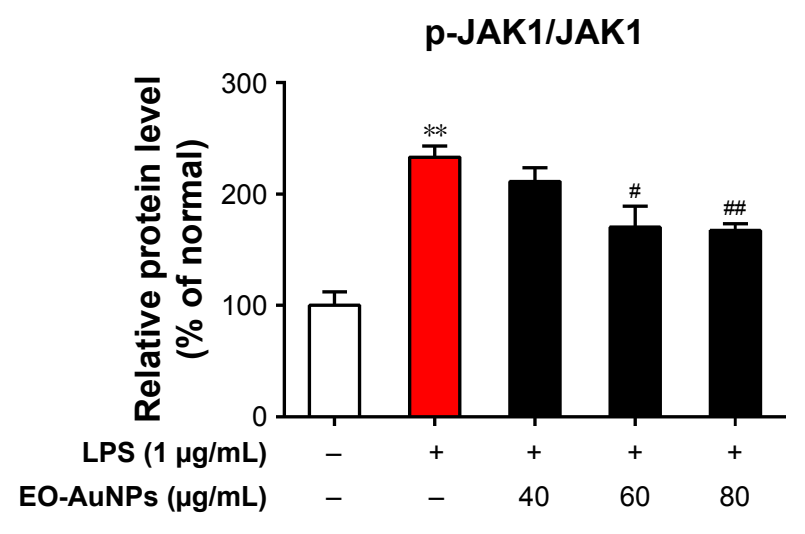

D

p-STAT3/STAT3

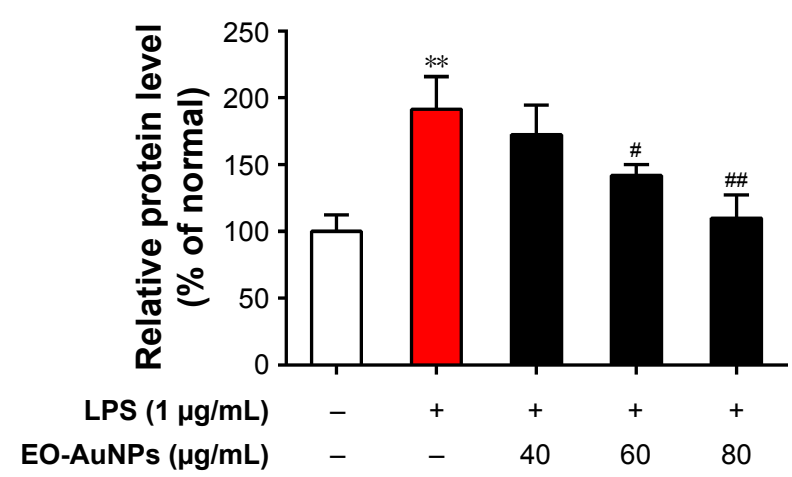

Figure 9 Effect of EO-AuNPs on JAK/STAT signaling-related protein expression in RAW 264.7 cells. (A) The proteins of P-JAKI, JAKI, P-STATI, STATI, p-STAT3, and STAT3 in LPS-stimulated RAW 267.4 cells were measured by Western blot analysis. (B-D) The band intensities for P-JAKI/JAKI, p-STATI/STATI, and p-STAT3/STAT3 were quantified and normalized to the corresponding value of $\beta$-actin. Densitometry data are expressed as percentage relative to the non-treated control and shown as mean \pm SEM. $* * P<0.01, * * * P<0.001$ compared to the non-treated control. ${ }^{*} P<0.05, \ldots P<0.01, \ldots \# P<0.001$ compared to the LPS control.

Abbreviations: JAK, Janus kinase; STAT, signal transducer and activators of transcription; EO-AuNPs, Euphrasia officinalis-gold nanoparticles; LPS, lipopolysaccharide; SEM, standard error of the mean.

the FTIR spectra of the EO-AuNPs revealed that the hydroxyl groups of phenolic compounds might contribute to bioreducing and capping for the synthesis of AuNPs. ${ }^{39}$

E. officinalis has been traditionally used for treating inflammatory-linked diseases, such as eye disorders, colds, coughs, and hay fever. ${ }^{27}$ Our previous results showed that the caffeic acid, luteolin-glucoside, rutin, and acteoside were tentatively identified by Ultra-High Performance Liquid Chromatography-Quadrupole Time-of-Flight Mass Spectrometry analysis. ${ }^{24}$ Till now, there is no report about physicochemical study of the EO-AuNPs and their cellular uptake pattern. In the present study, the synthesized EO-AuNPs were demonstrated to exhibit anti-inflammatory effects in LPS-stimulated RAW 264.7 cells. Previous studies have demonstrated that NPs could be internalized into macrophages by fluid-phase endocytosis. The overall uptake of NPs was described as a two-step process, including the binding of NPs on the cell membrane and the internalization of the reactive sites by an endocytosis pathway. ${ }^{32}$ Similarly, we found that the cellular uptake of EO-AuNPs started after 5 minutes and further localization inside the macrophages during the 3 hours of incubation was observed by an EDF microscopy system. Furthermore, TEM images of cells incubated with the AuNPs showed aggregated NPs both at the cell membrane and in primarily intracellular compartments resembling endosomes and lysosomes, while no AuNPs were found in the nuclei of macrophages. On the other hand, the cytotoxicity of AuNPs is still a matter of concern when they are used in biomedical applications. It has been suggested that AuNPs 1-2 nm in diameter were highly toxic, whereas those larger than 
$15 \mathrm{~nm}$ were comparatively nontoxic, irrespective of the cell type tested. ${ }^{42}$ Another report also showed that macrophages are highly tolerant to the cytotoxicity of anticancer drugs and NPs. ${ }^{43}$ In this study, no obvious cytotoxicity was observed at $20-80 \mu \mathrm{g} / \mathrm{mL}$ concentrations of EO-AuNPs, while a concentration of $100 \mu \mathrm{g} / \mathrm{mL}$ exhibited little cytotoxicity $(25.5 \%$ death rate) against RAW 264.7 cells. Therefore, EO-AuNP concentrations from 40 to $80 \mu \mathrm{g} / \mathrm{mL}$ can be used in our future work. However, the mechanism of entering into the lysosome or endosome needs to be studied clearly in our further study.

Macrophage-derived NO plays an important role in immunity and maintaining homeostasis, but all sorts of inflammationrelated diseases are caused by the overproduction of NO. ${ }^{44}$ Thus, iNOS, as a pivotal enzyme in the macrophages' inflammatory response, has a catalytic effect on the production of $\mathrm{NO}^{45}$ Therefore, the regulation of NO and iNOS is very important for screening anti-inflammatory agents. In our present study, at concentrations of $40-80 \mu \mathrm{g} / \mathrm{mL}$, EO-AuNPs effectively reduced LPS-induced NO overproduction and iNOS mRNA and protein expression in RAW 264.7 cells without producing any cytotoxicity. In addition to NO, various pro-inflammatory cytokines such as TNF- $\alpha$, IL-1 $\beta$, and IL- 6 have been known to be released by LPS-activated macrophages. ${ }^{46} \mathrm{EO}$-AuNPs also significantly suppressed the LPS-induced secretion of TNF$\alpha$, IL-1 $\beta$, and IL-6. A previous study showed that eye drops containing E. officinalis extracts exerted anti-inflammatory effects by effectively reducing the expression of IL-1 $\beta$ and iNOS in ultraviolet-B-irradiated corneal epithelial cells, which is consistent with the results of our study. ${ }^{27}$

To explore the molecular mechanisms further, the effects of EO-AuNPs on the LPS-induced activation of inflammatory signaling pathways were assessed. The transcription factor NF- $\mathrm{KB}$ is of great importance for the regulation of pro-inflammatory responses. Recent studies have shown that the phosphorylation and degradation of $\mathrm{I} \kappa \mathrm{B} \alpha$ lead to the activation of NF- $\kappa$ B in LPS-stimulated RAW 264.7 cells. Consequently, activated NF- $\kappa \mathrm{B}$ translocates to the nucleus, where it regulates the expression of inflammatory genes. ${ }^{6,47}$ In the present study, we found that EO-AuNPs exhibited anti-inflammatory effects by blocking the phosphorylation and degradation of $\mathrm{I} \kappa \mathrm{B} \alpha$ protein and by suppressing NF- $\kappa \mathrm{B}$ p65 nuclear translocation in LPS-challenged macrophages. Similarly, previous investigations have also proved that AuNPs decreased LPS-induced inflammatory mediators via the NF- $\kappa$ B signaling pathway. ${ }^{39,48}$

The JAK/STAT signaling pathway has an important role in the control of immune responses, as maladjusted JAK/STAT signaling is associated with various immune diseases. ${ }^{49}$ The activated STATs could translocate to the nucleus to regulate the expression of iNOS in RAW 264.7 cells. ${ }^{50}$ Several studies have shown that NPs inhibited LPS-induced inflammatory responses in RAW 264.7 macrophages and human peripheral blood mononuclear cells through the JAK/STAT signaling pathway. ${ }^{48,51}$ Thus, we evaluated whether EO-AuNPs could inhibit the activation of the JAK/STAT signaling pathway. In this study, EO-AuNPs were found to attenuate the LPS-stimulated phosphorylation of JAK1, STAT1, and STAT3 in RAW 264.7 macrophages.

Animal cell culture systems are regarded as sensitive indicators for exposure of nanomaterials. ${ }^{52}$ Preliminarily, the present study demonstrated the effects of synthesized EO-AuNPs on LPS-induced inflammation in RAW 264.7 murine macrophages. Further investigation on the antiinflammatory role of EO-AuNPs in human cell lines and in vivo animal models is therefore warranted.

\section{Conclusion}

In summary, the ethanol extract of E. officinalis leaves acted as a reducing and capping agent to successfully synthesize AuNPs. The synthesis of AuNPs using E. officinalis extract is useful not only because of their reduced environmental impact, but also because they can be used to produce large quantities of NPs. Physicochemical characterization confirmed the structural and chemical properties of the EO-AuNPs. In addition, we demonstrated that the EOAuNPs decreased inflammatory mediators and cytokine production by suppressing the NF- $\kappa \mathrm{B}$ and JAK/STAT activation in LPS-stimulated RAW 264.7 cells. Therefore, EO-AuNPs may be considered as a potential agent for the treatment of inflammatory disorders. A detailed study is needed to elucidate the anti-inflammatory effects of the biosynthesized AuNPs using the biomolecules present in E. officinalis extracts, which will be valuable to improve the properties of AuNPs.

\section{Acknowledgments}

This research was supported by the grant from the Ministry of SMEs and Startups (Grant number S2459805) and also supported by the grant "Cooperative Research Program for Agriculture Science and Technology Development (Project No PJ0128132017)” from Rural Development Administration, Republic of Korea.

\section{Disclosure}

The authors report no conflicts of interest in this work. 


\section{References}

1. Zhou Y, Wang J, Yang W, et al. Bergapten prevents lipopolysaccharideinduced inflammation in RAW264.7 cells through suppressing JAK/ STAT activation and ROS production and increases the survival rate of mice after LPS challenge. Int Immunopharmacol. 2017;48:159-168. doi:10.1016/j.intimp.2017.04.026

2. Förstermann U, Sessa WC. Nitric oxide synthases: regulation and function. Eur Heart J. 2011;33(7):829-837. doi:10.1093/eurheartj/ehr304

3. Wojdasiewicz P, Ła P, Szukiewicz D. The role of inflammatory and anti-inflammatory cytokines in the pathogenesis of osteoarthritis. Mediators Inflamm. 2014;2014:561459. doi:10.1155/2014/561459

4. Varga Z, Rafay Ali Sabzwari S, Vargova V. Cardiovascular risk of nonsteroidal anti-inflammatory drugs: an under-recognized public health issue. Cureus. 2017;9(4):e1144.

5. Wang Q, Kuang H, Su Y, et al. Naturally derived anti-inflammatory compounds from Chinese medicinal plants. J Ethnopharmacol. 2013; 146(1):9-39. doi:10.1016/j.jep.2012.12.013

6. Sharif O, Bolshakov VN, Raines S, Newham P, Perkins ND. Transcriptional profiling of the LPS induced NF- $\kappa \mathrm{B}$ response in macrophages. BMC Immunol. 2007;8(1):1. doi:10.1186/1471-2172-8-1

7. Son P-S, Park S-A, Na H-K, Jue D-M, Kim S, Surh Y-J. Piceatannol, a catechol-type polyphenol, inhibits phorbol ester-induced NF- $\mathrm{KB}$ activation and cyclooxygenase- 2 expression in human breast epithelial cells: cysteine 179 of IKK $\beta$ as a potential target. Carcinogenesis. 2010; 31(8):1442-1449. doi:10.1093/carcin/bgq099

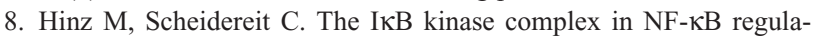
tion and beyond. EMBO Rep. 2014;15(1):46-61. doi:10.1002/embr. 201337983

9. Reiber C, Brieger A, Engelhardt G, Hebel S, Rink L, Haase H. Zinc chelation decreases IFN- $\beta$-induced STAT1 upregulation and iNOS expression in RAW 264.7 macrophages. J Trace Elem Med Biol. 2017;44: 76-82. doi:10.1016/j.jtemb.2017.05.011

10. Daraee H, Eatemadi A, Abbasi E, Fekri Aval S, Kouhi M, Akbarzadeh A. Application of gold nanoparticles in biomedical and drug delivery. Artif Cells Nanomed Biotechnol. 2016;44(1):410-422. doi:10.3109/216914 01.2014.955107

11. Draz MS, Shafiee H. Applications of gold nanoparticles in virus detection. Theranostics. 2018;8(7):1985. doi:10.7150/thno.23856

12. de Araújo Júnior RF, de Araújo AA, Pessoa JB, et al. Anti-inflammatory, analgesic and anti-tumor properties of gold nanoparticles. Pharmacol Rep. 2017;69(1):119-129. doi:10.1016/j.pharep.2016.09.017

13. Yang W, Shi X, Shi Y, et al. Beyond the roles in biomimetic chemistry: an insight into the intrinsic catalytic activity of an enzyme for tumorselective phototheranostics. ACS Nano. 2018;12(12):12169-12180. doi:10.1021/acsnano.8b05797

14. Zhang B, Wang J, Yu J, Fang X, Wang X, Shi D. Site-specific biomimetic precision chemistry of bimodal contrast agent with modular peptides for tumor-targeted imaging. Bioconjug Chem. 2017;28(2): 330-335. doi:10.1021/acs.bioconjchem.6b00712

15. Yang W, Wu X, Dou Y, et al. A human endogenous protein exerts multirole biomimetic chemistry in synthesis of paramagnetic gold nanostructures for tumor bimodal imaging. Biomaterials. 2018;161:256-269. doi:10.1016/j.biomaterials.2018.01.050

16. Bahadar H, Maqbool F, Niaz K, Abdollahi M. Toxicity of nanoparticles and an overview of current experimental models. Iran Biomed J. 2016;20(1):1.

17. Boisselier E, Astruc D. Gold nanoparticles in nanomedicine: preparations, imaging, diagnostics, therapies and toxicity. Chem Soc Rev. 2009; 38(6):1759-1782. doi:10.1039/b806051g

18. Herizchi R, Abbasi E, Milani M, Akbarzadeh A. Current methods for synthesis of gold nanoparticles. Artif Cells Nanomed Biotechnol. 2016;44(2):596-602. doi:10.3109/21691401.2014.971807

19. Ahmed S, Ikram S. Biosynthesis of gold nanoparticles: a green approach. J Photochem Photobiol B. 2016;161:141-153. doi:10.1016/j. jphotobiol.2016.04.034
20. Benedec D, Oniga I, Cuibus F, et al. Origanum vulgare mediated green synthesis of biocompatible gold nanoparticles simultaneously possessing plasmonic, antioxidant and antimicrobial properties. Int $J$ Nanomedicine. 2018;13:1041. doi:10.2147/IJN.S177627

21. Meserole L, Yarnell E. Botanical prevention and treatment for hay fever. Alter Complement Therapies. 1996;2(2):83-86. doi:10.1089/ act.1996.2.83

22. Novy P, Davidova H, Serrano-Rojero CS, Rondevaldova J, Pulkrabek J, Kokoska L. Composition and antimicrobial activity of Euphrasia rostkoviana Hayne essential oil. Evid Based Complement Altern at Med. 2015;2015:734101. doi:10.1155/2015/734101

23. Paduch R, Woźniak A, Niedziela P, Rejdak R. Assessment of eyebright (Euphrasia officinalis L.) extract activity in relation to human corneal cells using in vitro tests. Balkan Med J. 2014;31(1):29. doi:10.5152/ balkanmedj.2014.8377

24. Liu Y, Hwang E, Ngo H, et al. Protective effects of Euphrasia officinalis extract against ultraviolet B-induced photoaging in normal human dermal fibroblasts. Int J Mol Sci. 2018;19(11):3327. doi:10.3390/ ijms19113327

25. Levchenko L, Golovanova S, Lariontseva N, et al. Synthesis and study of gold nanoparticles stabilized by bioflavonoids. Russ Chem Bull. 2011;60(3):426. doi:10.1007/s11172-011-0067-1

26. Kim K, Han JW. Effect of caffeic acid adsorption in controlling the morphology of gold nanoparticles: role of surface coverage and functional groups. Phys Chem Chem Phys. 2016;18(40):27775-27783. doi:10.1039/c6cp04122a

27. Bigagli E, Cinci L, D’Ambrosio M, Luceri C. Pharmacological activities of an eye drop containing Matricaria chamomilla and Euphrasia officinalis extracts in UVB-induced oxidative stress and inflammation of human corneal cells. J Photochem Photobiol B. 2017;173:618-625. doi:10.1016/j.jphotobiol.2017.06.031

28. Lee S, Yu H, Kang SH. Selective fluorescent-free detection of biomolecules on nanobiochips by wavelength dependent-enhanced dark field illumination. Chem Commun. 2013;49(75):8335-8337. doi:10.1039/ c3cc44153a

29. Abbai R, Mathiyalagan R, Markus J, et al. Green synthesis of multifunctional silver and gold nanoparticles from the oriental herbal adaptogen: siberian ginseng. Int J Nanomedicine. 2016;11:3131. doi:10.2147/IJN. S108549

30. Singh P, Pandit S, Garnæs J, et al. Green synthesis of gold and silver nanoparticles from Cannabis sativa (industrial hemp) and their capacity for biofilm inhibition. Int J Nanomedicine. 2018;13:3571. doi:10.2147/ IJN.S177627

31. Pérez ZEJ, Mathiyalagan R, Markus J, et al. Ginseng-berry-mediated gold and silver nanoparticle synthesis and evaluation of their in vitro antioxidant, antimicrobial, and cytotoxicity effects on human dermal fibroblast and murine melanoma skin cell lines. Int J Nanomedicine. 2017; 12:709. doi:10.2147/IJN.S118373

32. Luciani N, Gazeau F, Wilhelm C. Reactivity of the monocyte/ macrophage system to superparamagnetic anionic nanoparticles. J Mater Chem. 2009;19(35):6373-6380. doi:10.1039/b903306h

33. Lee J-W, Chun W, Kwon O-K, et al. 3, 4, 5-Trihydroxycinnamic acid attenuates lipopolysaccharide (LPS)-induced acute lung injury via downregulating inflammatory molecules and upregulating HO-1/AMPK activation. Int Immunopharmacol. 2018;64:123-130. doi:10.1016/j. intimp.2018.08.015

34. Elavazhagan T, Arunachalam KD. Memecylon edule leaf extract mediated green synthesis of silver and gold nanoparticles. Int $J$ Nanomedicine. 2011;6:1265-1278. doi:10.2147/IJN.S18347

35. Yeh Y-C, Creran B, Rotello VM. Gold nanoparticles: preparation, properties, and applications in bionanotechnology. Nanoscale. 2012;4(6): 1871-1880. doi:10.1039/c1nr11188d

36. Hwang SJ, Jun SH, Park Y, et al. Green synthesis of gold nanoparticles using chlorogenic acid and their enhanced performance for inflammation. Nanomedicine. 2015;11(7):1677-1688. doi:10.1016/j.nano. 2015.05.002 
37. de Carvalho TG, Garcia VB, de Araújo AA, et al. Spherical neutral gold nanoparticles improve anti-inflammatory response, oxidative stress and fibrosis in alcohol-methamphetamine-induced liver injury in rats. Int $J$ Pharm. 2018;548:1-14. doi:10.1016/j.ijpharm.2018.06.008

38. Chen H, Ng JP, Tan Y, et al. Gold nanoparticles improve metabolic profile of mice fed a high-fat diet. J Nanobiotechnology. 2018;16(1):11. doi:10.1186/s12951-018-0338-1

39. Ahn S, Singh P, Jang M, et al. Gold nanoflowers synthesized using Acanthopanacis cortex extract inhibit inflammatory mediators in LPSinduced RAW264. 7 macrophages via NF- $\mathrm{BB}$ and AP-1 pathways. Colloids Surf B Biointerfaces. 2017;160:423-428.

40. Park SY, Chae SY, Park JO, Lee KJ, Park G. Kalopanacis Cortex extract-capped gold nanoparticles activate NRF2 signaling and ameliorate damage in human neuronal SH-SY5Y cells exposed to oxygenglucose deprivation and reoxygenation. Int J Nanomedicine. 2017;12: 4563. doi:10.2147/IJN.S138178

41. Salunke GR, Ghosh S, Kumar RS, et al. Rapid efficient synthesis and characterization of silver, gold, and bimetallic nanoparticles from the medicinal plant Plumbago zeylanica and their application in biofilm control. Int J Nanomedicine. 2014;9:2635.

42. Zhang Q, Hitchins VM, Schrand AM, Hussain SM, Goering PL. Uptake of gold nanoparticles in murine macrophage cells without cytotoxicity or production of pro-inflammatory mediators. Nanotoxicology. 2011; 5(3):284-295. doi:10.3109/17435390.2010.512401

43. Dreaden EC, Mwakwari SC, Austin LA, Kieffer MJ, Oyelere AK, El-Sayed MA. Small molecule-gold nanorod conjugates selectively target and induce macrophage cytotoxicity towards breast cancer cells. Small. 2012;8(18):2819-2822. doi:10.1002/smll.201200333

44. Sharma J, Al-Omran A, Parvathy S. Role of nitric oxide in inflammatory diseases. Inflammopharmacology. 2007;15(6):252-259. doi:10.1007/ s10787-007-0013-X
45. Aktan F. iNOS-mediated nitric oxide production and its regulation. Life Sci. 2004;75(6):639-653. doi:10.1016/j.1fs.2003.10.042

46. Park J-Y, Chung T-W, Jeong Y-J, et al. Ascofuranone inhibits lipopolysaccharide-induced inflammatory response via NF-kappaB and AP-1, p-ERK, TNF- $\alpha$, IL-6 and IL-1 $\beta$ in RAW 264.7 macrophages. PLoS One. 2017;12(2):e0171322. doi:10.1371/journal.pone.0171322

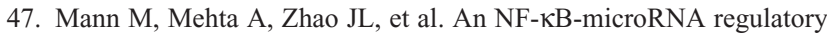
network tunes macrophage inflammatory responses. Nat Commun. 2017;8(1):851. doi:10.1038/s41467-017-00972-z

48. Ma JS, Kim WJ, Kim JJ, et al. Gold nanoparticles attenuate LPS-induced NO production through the inhibition of NF- $\kappa$ B and IFN- $\beta /$ STAT1 pathways in RAW264.7 cells. Nitric Oxide. 2010;23(3):214-219. doi:10.1016/j.niox.2010.06.005

49. Shuai K, Liu B. Regulation of JAK-STAT signalling in the immune system. Nat Rev Immunol. 2003;3(11):900. doi:10.1038/nri1226

50. Guo C, Yang L, Luo J, et al. Sophoraflavanone G from Sophora alopecuroides inhibits lipopolysaccharide-induced inflammation in RAW264.7 cells by targeting PI3K/Akt, JAK/STAT and Nrf2/HO-1 pathways. Int Immunopharmacol. 2016;38:349-356. doi:10.1016/j. intimp.2016.06.021

51. Yang H, Kozicky L, Saferali A, et al. Endosomal pH modulation by peptide-gold nanoparticle hybrids enables potent anti-inflammatory activity in phagocytic immune cells. Biomaterials. 2016;111:90-102. doi:10.1016/j.biomaterials.2016.09.032

52. Ambwani S, Kandpal D, Arora S, Ambwani TK. Cytotoxic effects of gold nanoparticles exposure employing in vitro animal cell culture system as part of nanobiosafety. 5th National Conference on Thermophysical Properties: (NCTP-09) AIP Conference Proceedings 1724, 020091201.
International Journal of Nanomedicine

\section{Publish your work in this journal}

The International Journal of Nanomedicine is an international, peerreviewed journal focusing on the application of nanotechnology in diagnostics, therapeutics, and drug delivery systems throughout the biomedical field. This journal is indexed on PubMed Central, MedLine, CAS, SciSearch $\AA$, Current Contents $₫ /$ Clinical Medicine,

\section{Dovepress}

Journal Citation Reports/Science Edition, EMBase, Scopus and the Elsevier Bibliographic databases. The manuscript management system is completely online and includes a very quick and fair peer-review system, which is all easy to use. Visit http://www.dovepress.com/ testimonials.php to read real quotes from published authors. 